This item was submitted to Loughborough's Research Repository by the author.

Items in Figshare are protected by copyright, with all rights reserved, unless otherwise indicated.

\title{
Discourse analytic practice
}

PLEASE CITE THE PUBLISHED VERSION

PUBLISHER

Sage Publications Ltd (C) The authors

VERSION

AM (Accepted Manuscript)

LICENCE

CC BY-NC-ND 4.0

REPOSITORY RECORD

Hepburn, Alexa, and Jonathan Potter. 2019. "Discourse Analytic Practice”. figshare. https://hdl.handle.net/2134/9488. 
This item was submitted to Loughborough's Institutional Repository (https://dspace.lboro.ac.uk/) by the author and is made available under the following Creative Commons Licence conditions.

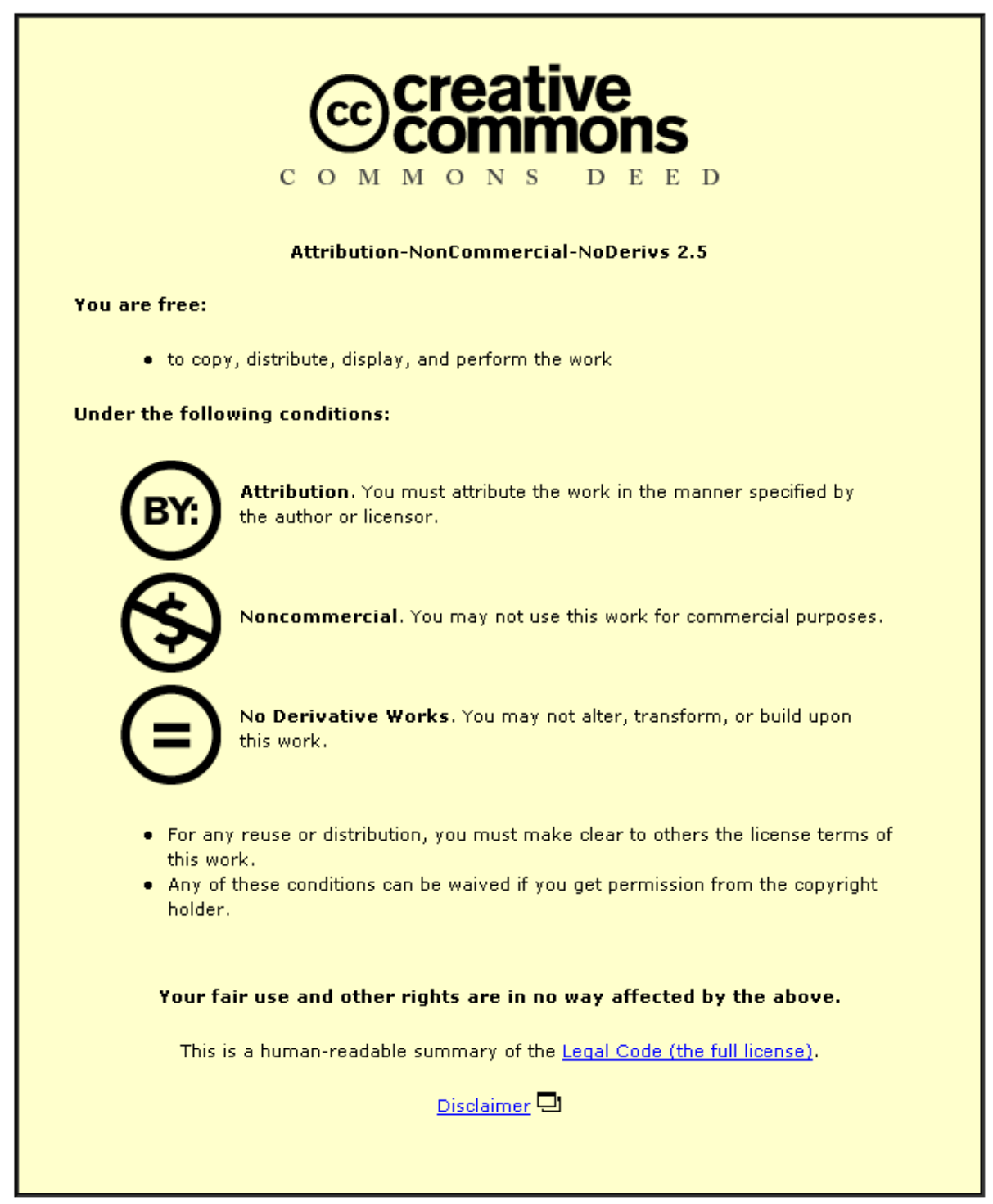

For the full text of this licence, please go to: http://creativecommons.org/licenses/by-nc-nd/2.5/ 


\section{Discourse ANALytic Practice}

\section{Alexa Hepburn \& Jonathan Potter}

Discourse and Rhetoric Group

Department of Social Sciences

Loughborough University

Loughborough

Leicestershire, LE11 3TU

Email: Al.Hepburn@lboro.ac.uk

Email: J.A.Potter@lboro.ac.uk

Fax: 01509223944

We would like to thank, Anssi Peräkylä, David Silverman and Teun van Dijk for helpful comments on an earlier version of this chapter. We would also like to thank all the people at the NSPCC - particularly John Cameron and Ann Johnson, and the various child protection officers - who generously offered time and trust for the research discussed here. This work was supported by a Fellowship from the Leverhulme Trust awarded to the first author.

For: C. Seale, D. Silverman, J. Gubrium \& Gobo, G. (Eds). Qualitative Research Practice. London; Sage. 
Jonathan Potter is Professor of Discourse Analysis at Loughborough University. He has researched a range of topics including racism, relationship counselling, and child protection helplines and has written extensively on meta-theory, theory and methods in the area of discourse analysis and discursive psychology. His most recent books are Representing Reality (Sage, 1996), Focus Group Practice (with Claudia Puchta, Sage, in press) and Talk and Cognition (edited with Hedwig te Molder, CUP, in press).

Alexa Hepburn is Lecturer in Social Psychology at Loughborough University. She has studied school bullying, issues of gender and violence against children, and interaction on child protection helplines, as well as writing about the relations of the philosophy of Derrida to the theory and practice of social psychology. She has written an integrative survey of critical social psychology: An Introduction to Criticial Social Psychology (Sage, 2003). 
It is an unusually sunny day in summer 2000 and we are sitting round a table in the small neat coffee room used by the professionals who field calls at the London centre for the National Society for the Prevention of Cruelty to Children (NSPCC) child protection helpline. There is a kettle, drinks machine, sink, microwave, water-cooler and a small bookshelf filled with a varied range of journals and writings on child abuse and social work. It is well decorated and new - not like our departmental coffee rooms! We have taken up residence for what seems like the whole of the hot afternoon and we are taking turns talking to a stream of people who are breaking off from fielding calls to talk to us. We have provisional support from the management team at the NSPCC to do research on the helpline - but we need people who actually work the phones - the Child Protection Officers or CPOs - to agree. We have to persuade them that our research is interesting, that it will not threaten their work, that we won't be judging them, that they might find it valuable to take part, and that the NSPCC might find it useful. We spent a bit of time that morning deciding what to wear - what gradation of 'smart casual' sends quite the right 'professional yet informal' message. It feels a little like being interviewed for a job. Everyone is friendly and attentive and most say yes, or at least say they are interested and will think about it. We spend a bit of time in ones and twos talking through the technical aspects of recording calls onto a Minidisk. How did we get here? How did/will things develop?

In this chapter we will try and give a different sense of a research project in the area of 'discourse analysis' (see Box 1). We will try and combine general observations about the nature of this kind of research and how it can be done with a feel for the contingent, local, practical nature of doing research. We will break this into segments that reflect to some extent the way research of this kind unfolds. But first: some philosophy and sociology. 


\section{Contexts of Scientific Understanding}

When writing about method there are different ways of understanding what the writing is for, and how it characterises research. On the one hand, there are methodology texts that lay out the logic of research in a way that can be drawn on to justify claims and procedures. On the other, there are writings about the actualities of developing research projects, the practice of qualitative research. This chapter is for a volume with the latter focus. It is worth thinking about this distinction in a bit more detail, and for that it is useful to consider a classic distinction used in the philosophy and sociology of science.

Up to 1970s the distinction between context of justification and the context of discovery was crucial for the way science was understood (Feyerabend, 1975; Mulkay, 1979). It is a subtle distinction. The context of justification referred to the way that any particular fact was justifiable by reference to empirical findings, the logic of investigation, the appropriate use of general criteria, theoretical coherence and so on. At one level, this is the stuff of scientific articles - where reference to findings, methods and so on are run through procedures of peer review before publication. At another level, this is the stuff of philosophers - where discussions of empiricism, progressive research programmes, and so on are part of the discussion of the special nature of scientific knowledge. In contrast, the context of discovery refers to all the contingent events and factors that led up to any particular knowledge claim. This is the stuff of psychological and sociological study - the psychodynamics of genius, the social processes that led to the appointment of a particular 
scientist at a particular institution, the political and funding background that favoured a certain kind of research.

This distinction suited the philosophy of science of the era as it allowed philosophers to consider the way knowledge is justified, without requiring them to perform historical analyses of the detail of what went on in a particular scientific episode. It was the logic that counted, and that could be assessed post-hoc. Sociologists could be left to sort out the other stuff which was important, but, somehow, not so fundamental. One of the features of the new philosophy of science (Chalmers, 1992) and the sociology of scientific knowledge (SSK; see Ashmore, 1989) was that this distinction started to crumble. In particular, it was concerned to show the contingent, social basis of basic features of justification such as mathematics, replication, criteria for theory choice, and observation. This had two consequences. First, it collapsed the distinction by making it very hard to justify looking at justification abstracted from the contingent and social world, the context of discovery. Second, and more broadly, it suggested a much more complex and rather more fallible view of science. It became harder to keep our understanding of science away from our understanding of everything else. To understand justification properly you need to look carefully at the detailed, practical contingencies of actual research.

There is another twist to this, however. More recent discursive psychology (DP) work on descriptions (Potter, 1996) highlights the way in which descriptions of events are bound up with doing actions, such as providing justification for actions and blaming others. Edwards' studies on relationship counselling show this up beautifully. When a husband and wife each describe what went on at the start of their relationship, the details of what is picked out, how events are sequences, the moments of vivid detail and broad brush gloss, work towards why, specifically, the other partner is the one who has the problems and needs the counselling, and should change (Edwards, 1995a, 1997, 1998). Now consider again the 
context of justification and context of discovery distinction. What SSK did was, in effect, show up the contingency of justification. What DP does is unsettle things the other way. It shows up the way contingency is constructed to do justification. It's a double whammy for the distinction!

How is this relevant here? It highlights the tricky nature of telling the real story of social research, of highlighting the practice. It makes it impossible (well, very hard!) to separate descriptions of practice from issues of justification. Telling a story of contingency almost invariably drifts into a story of justification. That does not mean we are not going to tell a story like that; we are just encouraging a sceptical stance on that story. Put another way, it makes it rather hard to interpret methods writing in social science. What is it for? Is it for guidance in practice? Or is it oriented to offering resources for justification? Is it a repository of claims and axioms that can be reproduced when building the legitimacy of some claim? When methods writings get cited, it is often in the latter way. The hope, of course, is that they are used by people to help with their practice, but that this support is less visible.

\section{Some history, naturally}

What led to our NSPCC research? Where do you start when tackling this question? With childhood, school, an inspirational lecturer, a brilliant book chapter? Let us offer some fragments. I got interested in discourse work and child abuse issues through doing a $\mathrm{PhD}$ on Derrida and teacher bullying (that is, bullying of children by teachers, rather than the more familiar kind). (Just a caution about the move into autobiography here - the ' $\mathrm{I}$ ' $(=\mathrm{AH})$ is a textual convenience, but that does not mean that we are buying the familiar story of authorship and psychology that often goes along with it. It is, to repeat, a textual convenience.) More recently we both got excited about the possibilities of work beyond 
interviews and ethnography. We had both analysed a lot of interviews, and $\mathrm{AH}$ had done a chunk of ethnography. The excitement was about a naturalistic social science (supported by discursive psychology and rhetoric; inspired by the success of conversation analysis) that would work with records of interaction and address a variety of questions that discourse analysts had used interviews to get at, and also moving beyond those to new questions that emerged from the material (see Box 2).

Box 2 interviews about here

One of the reasons often given for studying interviews rather than naturalistic materials is that interviews allow the researcher access to stuff that is too sensitive to get permission to study, or that occurs too rarely to realistically collect. Our experience, however, is that in practice permission can be gained if the right kind of approach is made. One of us (JP) had experience working with Mick Roffe on his PhD on social worker's assessments of parents whose children had been taken into care due to physical or sexual abuse (Roffe, 1996). Mick was able to get permission from all involved in this most sensitive of settings to use tape recordings or even video in some cases. One of us (AH) had experience working with Ceri Parsons who started her PhD on gender reassignment. Again, she was able to get permission to record first assessment interviews, where applicants were questioned about their reasons for wishing to change gender. Often, the argument is made that material is too sensitive without having tried to obtain permission. Persistence combined with creativity is the order of day here - keep trying new sites and think about how the theme of interest might appear in different settings.

Our NSPCC study also had its origins in PhD work. I (AH) was supervising Sam Bishop who wished to study children's accounts of bullying. She and I spent some time 
thinking of different settings where issues of bullying emerge - in schools, for example, or families. She and I identified ChildLine as a setting with a lot of potential that fitted both our interests. It is a high profile service that deals with large numbers of reports of abuse, talking through problems and advising children. After an exchange of letters we met ChildLine staff to discuss issues of access. Their response was mixed. On the one hand, they were interested in the work and could see a number of possibilities for application. On the other, they were concerned about the assurances of confidentiality in their advertising. They deliberated with their board of directors over possible ways of dealing with these problems, but eventually did not feel able to provide access. However, they were interested enough in the research to offer Sam Bishop access to their ongoing training sessions in peer counselling for school bullying; this is a fascinating research topic in its own right.

On the basis of this experience, I decided to approach the UK’s NSPCC. They have a rather different brief to ChildLine. Their role is less centrally to counsel children (although they may do that); rather it is to receive information about abuse and act on it (normally by passing it to the appropriate Social Services department, sometimes by contacting the police). The letter I sent has evolved through a number of projects. The generic form of this letter is reproduced in Figure 1. It is meant to get straight to the worries that potential research participants might have in collaborating with work of this kind. In particular, how are issues of ethics, consent and anonymity going to be managed? what extra work will be involved? how might the work be useful? Implicitly, it is also heading off the idea that the role of the research is to criticise the organization or its individual workers.

Figure 1 about here 
Our experience with previous studies is that it is the professionals (the counsellors, social workers, therapists) who are most wary of being researched; although they often identify the clients as the ones who have a problem. There are probably a number of reasons for this. Professionals may feel that the adequacy of their work is being questioned. This may be exacerbated by their common feeling that their own performance does not match ideals presented in training materials, or their fantasy of the ideal job. David Silverman (1997) refers to this as the problem of the Divine Orthodoxy. Practitioners are condemned to fail as they are compared to an idealized, normative standard of 'good communication', say, completely removed from actual practice. This was the clearly the case with Mick Roffe's social worker participants who worried that their work practices were messy; yet one of the features of his work was to highlight the way apparent disorganization in their practices was a result of their subtle management of a number concurrent tasks (Roffe, 1996). The letter in Figure 1 is designed to address these concerns in an accessible manner.

The next stage in the process of gaining access with the NSPCC was to follow up the letter with a face-to-face interview. The managers at NSPCC were interested and open enough to see what I was like in person. I met the manager of the helpline - John Cameron the senior researcher - Sue Creighton - and the head of training - Sylvia Tadd - at their London office. I went in with a checklist of their likely concerns to address as well as information about other research projects I had been involved with and the type of academic output I had produced. I was also prepared to address what would be one of the most difficult issues, that of ethics.

There are a number of tensions and complications with ethics in this area. There are different parties to the helpline interaction whose anonymity needs to be protected in different ways and, perhaps, for different reasons. The Child Protection Officers (CPOs) needed to have their identity hidden so that the research did not become confused with issues 
of promotion and evaluation. My role was research, not staff appraisal. Second, there were the callers; it was crucial that the research did not disrupt the often very delicate reporting process. The first group were easiest in practical terms. And this brings us back to the start of this chapter and also the point where we started to do the project jointly.

All potential CPOs for the study were briefed about it and given the opportunity to ask questions. They could opt into the research by working with the phone prepared for recording, but there was no pressure to do so. At the start of the project CPOs were typically (and understandably) cautious, and only a few signed up. As time passed and they got to know us, they became more confident that our aim was not to expose their (imagined) inadequacies more signed up. At time of writing more than twenty CPOs have recorded more than two hundred calls.

The callers raised a trickier ethics issue. We had initially floated the possibility of either a generic or selective recorded message as they called in noting that the calls might be recorded for research and training, and asking callers to explicitly say if they wanted to opt out of this. Such a message could have provided more detail as necessary. The managers at NSPCC were (quite appropriately) concerned that this would not allow callers to ask questions about the research that might concern them. They suggested that when CPOs took part in the study they asked the callers at the start of the call if they would mind their call used for research and training, and assured them anonymity. This had the disadvantage to us of producing disruption at the delicate point of call opening, although it turned out to be relatively minor in practice. We wrote out an ethics script for the CPOs to use; however, the managers suggested that each CPO develop their own version of this. In practice, this works well as CPOs can tailor it to particular callers (children, say, or people with communication problems). Sometimes the ethics segments of the call are quite brief, sometimes there is an extended set of questions and answers. From our perspective, this approach satisfies our 
appropriate professional guidelines (laid out by the British Psychological Society) and works for the NSPCC.

\section{Technology, Sampling and Questions}

Some readers will wonder that we are several pages through this chapter and we have talked about a lot of things, but not mentioned research questions yet. To some extent this reflects a move in discourse analysis, and particularly in discursive psychology, to considering a setting or a set of practices rather than starting with a question. This reflects a move from the traditional social science question of 'how does $\mathrm{X}$ influence $\mathrm{Y}$ ?' to the question 'how is $\mathrm{X}$ done?' In this case, we are moving away from questions such as 'how does social class influence the incidence of child abuse?' to 'how does reporting abuse get done?', 'how do CPOs deliver appropriate advice?', 'how do they keep highly upset callers on the line long enough to give evidence for police officers or social workers to act?'

There is also a theoretical context for these questions. Discursive psychology is concerned with the role of talk and texts in social practices. However, it also takes a particular theoretical perspective on this topic (Box 3). This focus on action orientation, situation and construction is one of the reasons why work has moved toward study of naturalistic materials (where, however far off the ideal, the attempt is to get at things that would have happened without the intervention of the researcher).

Box 3 theoretical principles about here

These broader issues have consequences for the type and quantity of data that we wished to collect and the technology used. In terms of technology, the prime material would 
be recordings of actual calls. We did not do formal interviews with the CPOs, for example, nor ethnography in the call centre. Having said that, we were not trying to avoid talking to CPOs or remain ignorant of issues to do with work practices, training, organizational structure and so on. I (AH) have spent a considerable time over two years hanging out with CPOs, chatting to them, and watching them at work. I do not want to call this ethnography or interviews, however. The topic of the research is the business of the calls, the recordings are the prime source for understanding that. The records of calls are the basis for supporting any research claims. What was learned by spending time on site is a resource for understanding, but is analytically secondary. Put simply, we want to avoid claims like the following - it looks like what is going on in this call is $\mathrm{X}$, but our ethnography/interviews shows that it is, in fact, Y. If it is, in fact, a Y, the hanging out may help us get there, but we want to be able to justify the claim with the public material, otherwise we will doubt its veracity. For the most part he recording is a more reliable basis for understanding what happens in the calls than the CPOs recollections of what happens in the calls, their assertions about what generally go on, or the researcher's own notes and post hoc reconstructions.

This is a subtle and easily misunderstood point as it can seem counter intuitive. And it relates to the live debates among discourse workers on the status of context (Billig, 1999; Schegloff, 1997, 1999; Wetherell, 1998). For researchers who see the process of analysis as one that involves contextualizing the study of discourse within a broader analysis of social context (like many in critical discourse analysis) the issue is how this analysis of context will work. In particular, there is a tension between the sorts of analysts' descriptions of context that come from ethnography and the sorts of detailed study of how descriptions are being used in calls. On a more prosaic level, different CPOs offered different glosses on precisely what their job was and how they acted on the phone. These glosses were insightful and 
interesting, but we were cautious about using them as a definitive guide to what was happening in the calls.

None of these high level questions would be very important if we could not make decent records of the calls. We opted to use MiniDisk recorders because of the high quality digital recordings they produce and because of the length of recording - more than two hours in mono. We set up two workstations in the call centre with MiniDisks, taking a lead directly from the phone socket (various adapters are available from electronics stores for doing this). We produced our own smartly coloured and laminated instruction guide, pared down to the bare essentials; and talked the volunteers through the use of the recorders. Inevitably this was not always sufficient. Over time the CPOs managed to do a wide range of things to that messed up recordings. Even after further training and new instructions it is not uncommon to pick up a blank MiniDisk. However, the quality of the recordings makes it all worthwhile.

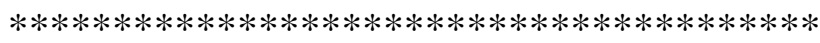

Box 4 digital records about here

How much material should we collect? This was very hard to tell in advance. However, we had some general considerations that guided our collection. First, we were concerned that different individual CPOs might have different styles on the phone. So we wanted to collect calls from different CPOs. Second, we were concerned that different categories of CPOs might be consequential - for example, it might be different reporting sexual abuse to a woman CPO than a man. Third, we were concerned to study some phenomena that turned up only rarely in the calls. For example, we were interested in calls from children reporting abuse, which make up around $10 \%$ of the total. Or, to take a more extreme case, we were interested in examples where callers were reporting abuse strongly linked to an ethnic category. The CPOs described these as particularly difficult calls that 
raised important questions. But we have found them to make up less than $1 \%$ of the total. However, by collecting a large amount of material appreciable instances of rare phenomena can be collected.

\section{Transcription}

Transcription is indispensable. However fluidly new technology allows you to use sound and video files, transcript has major advantages: you can write on it, read it in the bath, and publish it in traditional printed journals. The general system developed by Gail Jefferson (and well described in ten Have, 1998 and Hutchby \& Wooffitt, 1998) is the de facto standard in discursive psychology and conversation analysis. And for good reason - it has evolved in parallel to thirty years of research considering what features of talk are interactionally live. Where there are deviations from this it is with the use of Jefferson-Lite, particularly in interview studies on critical topics. Such transcript downplays the interactional nature of discourse, and has been more popular with analysts who take a more Foucauldian perspective. Even there, researchers are starting to see the need for high quality transcript. It is not a matter of being fussy or putting in detail that is not needed, but of having a closer record of what actually went on rather than a record that suggests something else went on!

Having emphasised the importance of quality transcript, there are practical limits. The various funding bids we put in for different parts of this project did not provide the several thousand pounds needed for full transcription of a large corpus of calls. We decided to use the smaller amount of money to get 'first pass' transcription (without intonation, emphasis, breathing, overlaps etc.). This raised another difficulty because of the sensitive nature of the material. We opted for a transcription agency that already handled sensitive legal and child protection work for courts and social services. The advantage of an agency 
like this was speed - they worked from calls burned onto CD and turned them round in a matter of days. These first pass transcripts were useful for getting an overall feel of particular calls and to identify broad episodes that might be of interest. They had one feature that made them superior to Jeffersonian transcripts. As they were orthographic, without the words broken up with colons or arrows, they were searchable for particular words or phrases.

There was no getting away from the need for better transcript, however. And there was no alternative to doing it ourselves. We started with a small number of very different calls to have data sessions with and get us into the material. After that the transcription has been bound up with the process of coding and doing particular studies.

\section{Coding and developing a study}

Let us return to our problem distinction between context of justification and context of discovery for a moment. We started off with some ways in which the distinction collapsed in on itself, with the justification being grounded in social processes, and the discovery accounts organized to provide justification. Despite the problems, the distinction makes practical sense when trying to describe the process of doing research. What you do does not fit into the sort of neat accounts that appear in methods sections of articles or in philosophical reconstructions of research. Nevertheless, there is a sense to seeing the more chaotic stabs at doing studies being reconstructable in a coherent and justifiable manner. That coherence makes the logic of what goes on more accessible to the reader of the article or book. Let us take one example paper from the overall project and try and offer a bit of natural history and bit of justification.

Soon after we started the NSPCC research some researchers in the general helpline area got to hear about it, and invited us to write a chapter. It was somewhat too early, and we 
had hardly done any transcription, let alone analysis. We produced a rough chapter that ended up not being suitable for the book. However, as is common with these things, the attempt to fulfil a particular brief set off some ideas. It got us particularly interested in issues that arise when callers are giving a first version of the abuse they are reporting, and the way they manage potential problems that arise using psychological descriptions. Our prior interests in problems with cognitive interpretation of mental terms and the delicacy of talking about violent acts were also guiding our early writing. As the study developed it became more and more focused on the construction of 'concern' and the role such constructions play in reporting abuse (Potter \& Hepburn, 2003).

The 'concerns' article evolved into its final state through a series of conference and departmental presentations. The most intensive development was between a presentation in Copenhagen and one a week later in Finland. Those few days were some of the most intensively engaged with the data over the period of the project. The intensive refereeing by people at Research on Language and Social Interaction provided the impetus for further refinement. It is very hard to do justice to the complexity of the actual development - the context of discovery in those terms - so lets move to a more cleaned up context of justification to make the whole thing more accessible. The abstract of the published article is reproduced in Figure 2 as a backdrop.

Figure 2 abstract about here

One of the first tasks in doing this study was one of data reduction. With an evergrowing set of calls, some of which lasted more than half an hour, the labour of transcription and analysis is potentially huge. The risk is in losing the specificity of what is going on while trying to encompass too much material. We (eventually) settled on a corpus of 50 openings 
that reported abuse to a third party. Even producing a corpus as seemingly clear cut as this was not easy. Various calls that seemed to be reporting abuse turned out (sometimes only after a lot of consideration) to be doing something else (e.g. complaining about social services). The corpus kept shrinking, and new calls had to be pulled in to keep it to size. Various general considerations were also in play in developing this corpus - it should not over-represent any one CPO; it should include both male and female CPOs and callers; it should include child as well as adult callers. We were also influenced by the pragmatic simplicity of working initially with calls that had already been transcribed by the transcription service.

This 50 call opening corpus was refined. A full Jefferson transcript was produced of each opening. An MP3 sound file of each opening was also produced. This meant that there was a working set of transcripts and recordings focused on openings that could be fluidly analysed.

\section{Analysis and justifying conclusions}

The temptation when writing about analysis is to focus on the things that are easy to describe. For example, we did a range of simple counts as an aid to understanding the patterning of the way constructions using the terms 'concerned' and 'concern' were used. At the broadest level, it was interesting to consider how specific to the NSPCC data concern constructions were. To check this we did something very simple, which was to compare prevalence in the NSPCC calls with a corpus of everyday phone calls (collected by Liz Holt).

The terms ‘concern' and 'concerned' appear an average of 7 times per call in our material, but only 0.3 times per call in the Holt corpus. At a more specific level we were interested in the prevalence of concerns constructions in the call openings, and also how many were 
initiated by the caller and how many the CPO. About $60 \%$ of openings use concerned constructions, about two thirds of these were initiated by the caller, and about a third by the CPO.

These counts were certainly interesting, and highlighted some things to follow up. But their implications are not conclusive on their own. Indeed, they are most unclear without considering the specifics of the interaction and how it unfolds. The course of analysis works through developing ideas about what is going on in some materials ('hypotheses' in rather grander methods speak) and exploring them, seeing how far they make sense. Again, the abstract logic of this is rather different from the ad hoc working at it that goes on in practice. When we were doing this analysis we had periods of sitting with a pile of transcripts arguing over what was happening and getting excited about things that seemed to work and depressed about dead ends. We would listen to an extract several times checking whether it made sense with our most recent idea. Often one or other of us would listen to extracts on headphones while scrolling through the transcript. As points of interest (or trouble) came up, we would use the post-it note facility on the word processor to annotate the transcript file. This is a particularly helpful facility where more than one people are working with a single transcript. Sometimes we needed to go back through the entire fifty transcripts and sound files to check that something that shouldn't be there wasn't there.

This all seems a bit abstract. Let us illustrate it with some of the material. The following is what we came to identify as a canonical call openings. This is a very simple example.

LB neighbour concern

1 CPO: Hello NSPCC Helpline can I help you?

2 Caller: Good afternoon >I wonder if you

3 could $<$

4 CPo: Yes [ certainly, ] 


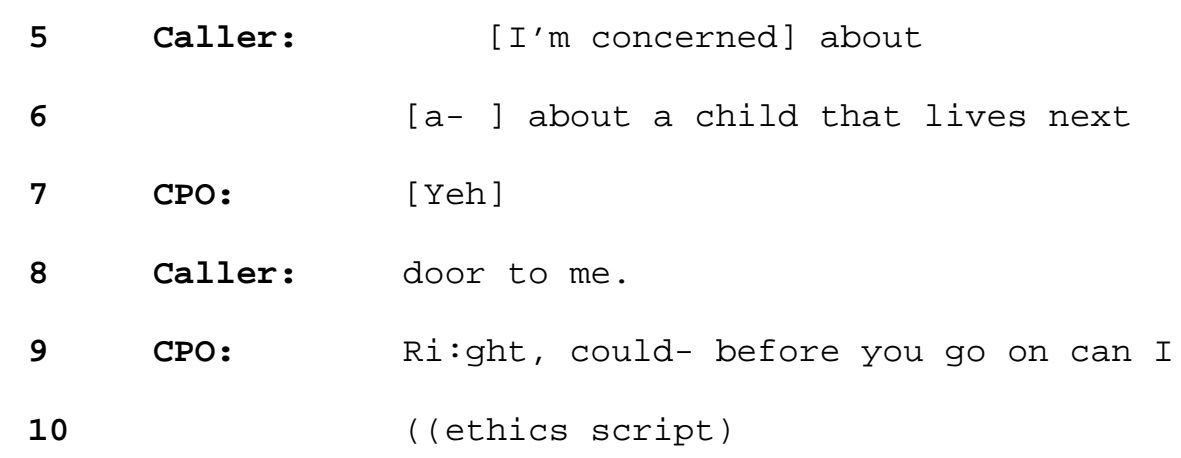

We started to call this form of opening 'canonical' because of its regular appearance in part, but, more importantly, because of the standard work it did.

Over the course of analysis we developed a number of ideas about what concerns constructions might be doing in these call openings. First, in line with our interactional focus, we considered the way that concerns constructions work to initiate unpacking. That is, 'I’m concerned about a child that lives next door' prefaces a sequence where the caller details the grounds for this concern. Second, it orients to criss-cross asymmetries in the interaction; the caller knows about the abuse; the CPO knows about child protection, evidence etc. It treats the actionable status of what is to be reported as not yet established, allowing it to be established in the interaction with the CPO. The other side of this coin is that it heads off a problem that might arise with direct opening announcements ('a child next door has been sexually abused'), which is that the next turn from the CPO would likely be a question about the basis of that knowledge. Third, concerns constructions display the caller's stance to the abuse - it is serious, critical, and, well, concerned. They are managing their own stance as reporters (something discursive psychologists have highlighted as particular important Edwards \& Potter, 1992). Fourth, and perhaps most importantly, concerns constructions allow the CPOs to treat abuse claims as serious without having to assume that they are true, accurate or actionable. The concern opening can evolve into a discussion of specific things in the world - injuries, times, family relationships - or into a discussion of, broadly, the psychology of the caller - their heightened anxieties, confusions or misperceptions. 
How did we develop these ideas, and how did we provide support for them with the material? The most important way was to use the way individual calls unfolded, turn-byturn, and the pattern across the whole the corpus of calls as a resource for checking ideas. There is a lot of detail in the article on this, so let us just take a couple of examples.

One thing that interested us was a class of openings where the caller had not started off with a concerns construction, but the CPO glosses the caller as having concerns. Here is an example. The extract starts at the point where the CPO has finished running through the ethics script.

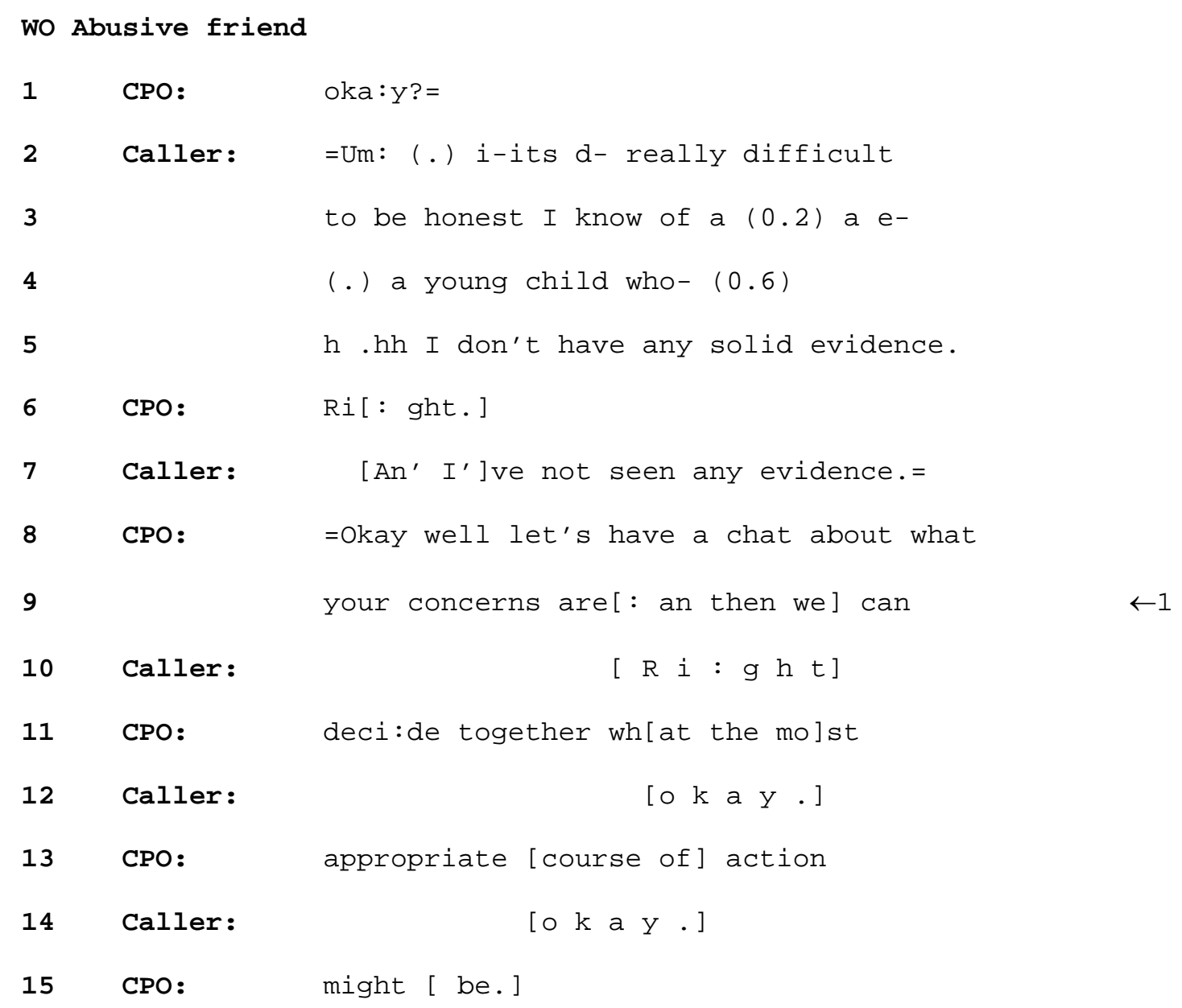


$[a h a$,

There are a couple of striking things about this example. Particularly interesting is the trouble shown in the caller's opening in lines 2-5. She prefaces her position as 'really difficult'; she identifies a child but breaks off before saying what has happened to him or her, and then notes her lack of evidence. This broad-brush description of the turn understates the trouble we see when looking carefully - note the delays, breathing and false starts, and the insertion of 'really' into 'its difficult', upgrading it. Now consider what the CPO does. Instead of directly addressing individual elements of the caller's opening, she proposes a 'chat about what your concerns are' which will allow the caller and CPO to 'decide together' on a course of action. The informal softened 'chat' (not statement taking, say, or report giving - cf. Antaki, 2000) combined with the egalitarian 'decide together' provide a sympathetic response. Most interesting for us, however, was the concerns construction. In effect, the CPO cleans up the caller's troubled opening, and prepares for a relaxed and collaborative unpacking of 'concerns'.

One of the things that is most productive in analysing discourse is the study of deviant cases. So we paid particular attention to the 20 calls that did not use concerned openings.

Did they refute the pattern, and the interactional business that we proposed to account for the pattern? Or did they mark out a range of alternatives and cases that provided further confirmation of the central analysis? We therefore as much time considering these exceptional cases. Let us take one class of exceptions to illustrate the style of analysis.

A subset of calls without concerns constructions started with the caller invoking an institutional identity. Here is an example:

JX Health visitor

1

((phone rings))

2 CPO:

Hello NSPCC can I help you? 


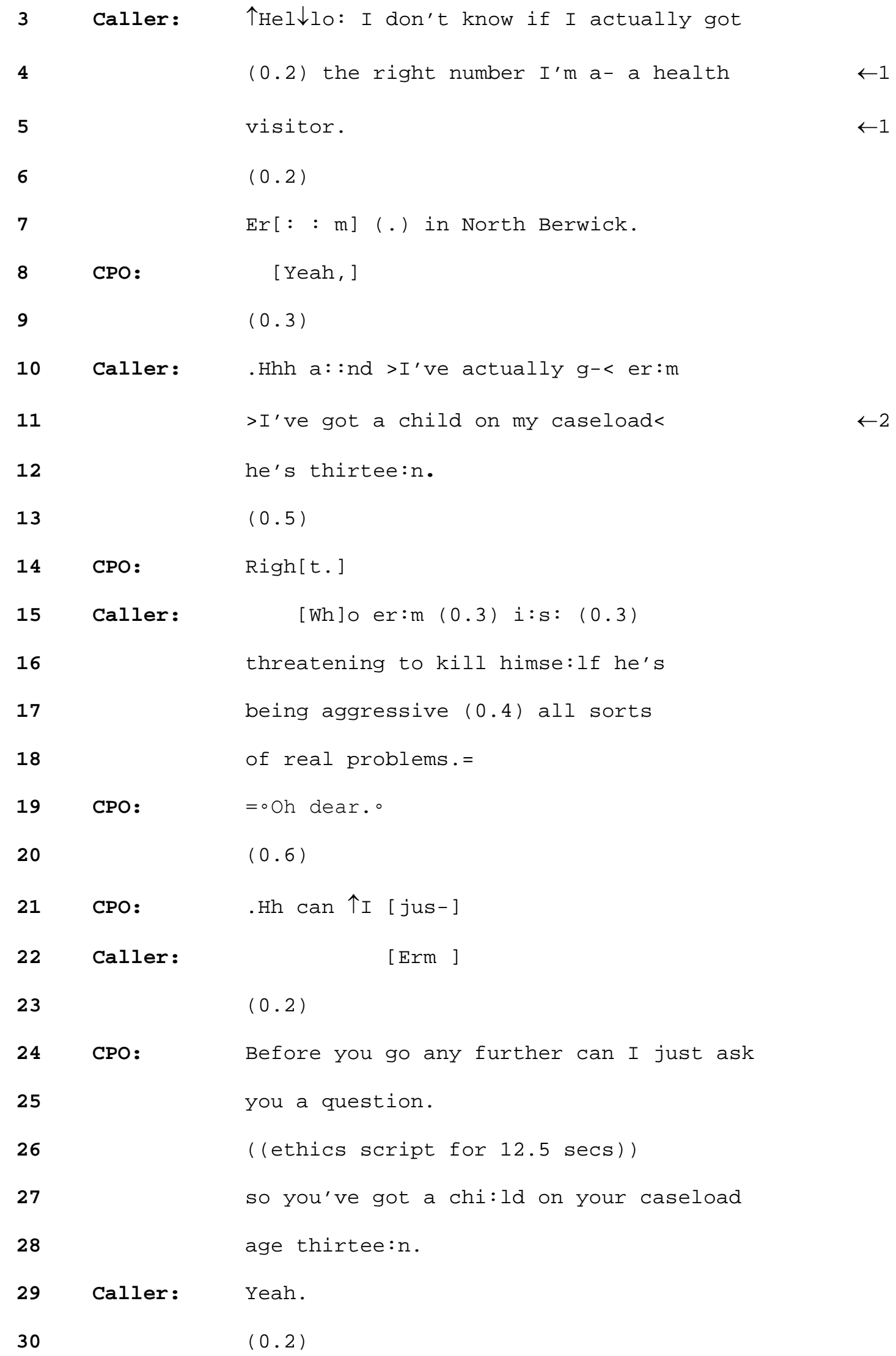

What excited us about this and similar examples was the way the institutional callers did not open with concerns constructions. Rather, they opened with their institutional identity. Note 
also the detail here - their description of the victim as 'on my caseload' formulates an institutional relationship (this contrasts to neighbour, grandchild and so on that characterise the canonical openings). And this is picked up by the CPO, who repeats the institutional formulation when they get things back on course after the ethics script.

This made perfect sense to us. The institutional callers had much less need to manage their stake and interest with respect to the abused as their interest is institutionally provided for (health visitors are meant to be concerned with the health of children). They did not have the same requirement to preface asymmetrical unpacking of the abuse report. In the example above, for example, note the way the caller gives a series of specific descriptions at the outset (e.g. 'he's threatening to kill himself'). The important analytic point is that analysis of these deviant cases did not undermine our initial idea (although it might have!); rather, it provided further confirmation. The business that the professional callers did not need to do provided further confirmation of the kinds of business that the lay callers did need to do. It provided further confirmation of the value of concern openings for lay callers.

Box 6 DA, ethnomethodology and CA

The examples we have given above relate to validation through considering participants' orientations and deviant cases. However, an important part of the process involves readers' evaluations. There are various arenas for this. The various conference presentations we gave offered researchers from a variety of different perspectives the opportunity to suggest different accounts of what was going on the material (and their effectiveness in doing this is marked by the extent in which the paper changed from its earliest draft). Then the journal referees who considered the submitted paper had the opportunity for the most intensive and consequential read. For example the editor and 
referees at Research in Language and Social Interaction provided several pages of detailed comment and some reanalysis. The general point, though, is that in this kind of work the materials under analysis are presented as carefully and completely as is feasible given constraints of space and time. In conference settings we gave out the extracts on handouts and played the sound (suitably anonymised). The submitted article contained a range of examples. This gives the readers the opportunity of not merely being unconvinced by the analysis but finding features that contradict it. This is a different kind of challenge, and a different style of validity than that found in a lot of other areas of social science and psychology.

\section{Application and utility}

Application and utility are tricky areas. But they are important and often neglected, so they are worth dwelling on at the end of this chapter. We are cautious about the assumption that utility is necessarily a good thing, or is the proper test of good work. The danger is of losing sight of broader political questions about who is using the work and for what. Some of the most challenging social science is not usable in a clear way; but it might do something else, such as offer a different vision of social organization and social change. In the discourse area, we would see Michael Billig’s (1992) Talking of the Royal Family as an excellent example of this. It offers an alternative way of understanding conversation, ideology and the way social relations are legitimated.

Our own study might seem to be rather more tightly focused and small scale than this. Indeed, I (JP) had an interesting discussion with a $\mathrm{PhD}$ researcher (Mandi Hodges) who was concerned (!) about its lack of practical use. Let us try and address that. It is quite complicated. Application is often measured against a picture of the application of knowledge 
which does not work in natural science, let alone social science. Social scientists are often surprised about how difficult it is to chart specific applications from specific advances in the natural or biological sciences (Potter, 1982).

Our study of abuse call openings is very specific and detailed; yet it has a broader theoretical aim which is to contribute to a body of discursive psychology that is questioning the way cognition is understood in psychology (e.g. Edwards, 1997). This broader intellectual and scientific debate about how persons and psychological stuff should be conceptualised and analysed seems to be fundamental in psychology and social science. The outcome (whatever it is) will be hugely influential not just for specific research, but for the way disciplines such as psychology input into social services, education, organizational life, counselling and so on. This is a big practical consequence - although this one paper, of course, will not do much on its own. This is a debate being shaped by many participants with different styles of research and positions.

Nevertheless, (with apologies to Mandi) the Mandi Hodges challenge can still be directed at the study. Lets sharpen it up. The suggestion is that the paper seems to be all about talk, and little bits of it at that, but somehow missing the vulnerable children that are the whole point of it all. How might it actually help the NSPCC do their job? Here are some thoughts.

First, and most specifically, the paper helps us understand why certain callers might get into trouble. For example, the one call opening in our corpus that deviates from both the canonical pattern and its standard alternatives was made by a young child. Note the way she announces the nature of the abuse in the opening (line 5); and note that the CPO is then in a position of doing something tricky which is asking for the basis of this knowledge (lines 1112). Although the NSPCC need this information to be able to follow up on a call like this adequately, it is still easily heard as displaying a sceptical stance to the child. 
BN Two 12-year-old girls

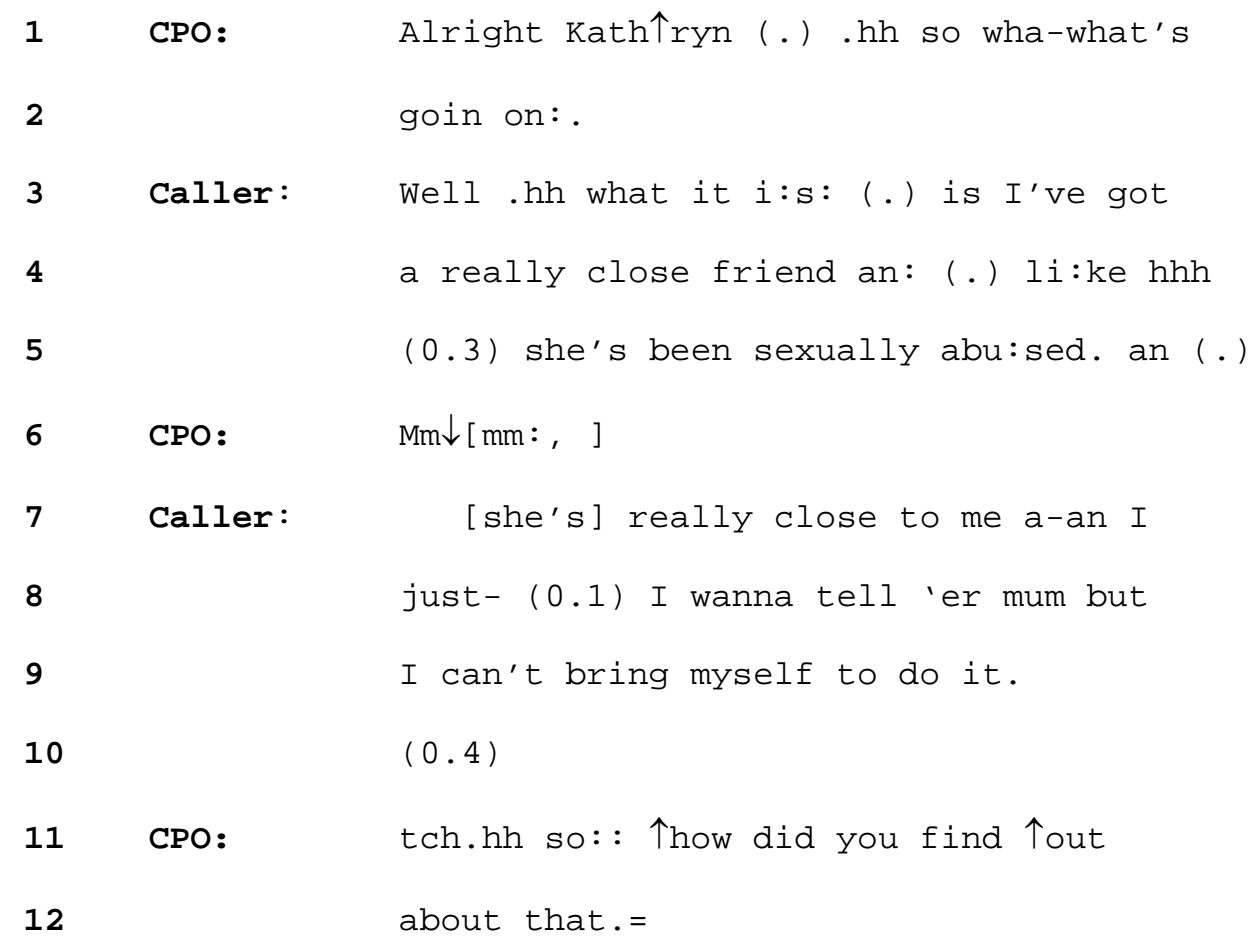

The paper provides an analytically grounded account of why problems might appear in calls such as this, and therefore suggests directions for thinking about how CPOs might counter them.

More broadly discourse studies of this kind aim to explicate the organization of NSPCC calls, and the different sorts of business done by that organization. Understanding this should make a positive input into training. One of the limitations of training for work like that done by the CPOs is that it is often based on idealizations or suppositions about the way interaction works. We found that elsewhere in a study of focus group moderation - the claims in training manuals are often quite different from what we identified as good practice (Puchta \& Potter, in press). One thing we found with this project was that the initial practical input was rather simple. We were able to provide CPOs with a set of digitised and roughly transcribed calls on a CD that they could play in their own PC (stopping and starting, dipping into and so on). Some of the CPOs found that the facility to reflect on her or his own practice was very helpful. We hope that toward the end of the research we can provide more 
sophisticated training aids which allow CPOs to step through digitised calls with analytic observations and suggestions about them (e.g. about trouble and its solution). Silverman (1998) has argued that practical input into training of this kind are an important way for the application of interaction research. The aim of these kind of practical interventions here is not to tell the CPOs how to do their job better, but to provide one sort of resource that they can draw in their training and practice as is helpful. 


\section{REFERENCES}

Antaki, C. (2000). Two rhetorical uses of the description 'chat'. M/C: A Journal of Media and Culture, 3. http://www.api-network.com/mc/0008/uses.html

Ashmore, M. (1989). The reflexive thesis: Wrighting sociology of scientific knowledge. Chicago: University of Chicago Press.

Billig, M. (1992). Talking of the royal family. London: Routledge.

Billig, M. (1999). Whose terms? Whose ordinariness? Rhetoric and ideology in conversation analysis, Discourse and Society 10: 543-558.

Button, G. \& Sharrock, W. (1993). A disagreement over agreement and consensus in constructionist sociology. Journal for the Theory of Social Behaviour, 23 (1), 1-25.

Chalmers, A. (1992). What is this thing called science?: An assessment of the nature and status of science and its methods, 2nd Ed.. Milton Keynes: Open University Press.

Edwards, D. (1995a). Two to tango: Script formulations, dispositions, and rhetorical symmetry in relationship troubles talk. Research on Language and Social Interaction, 28 (4), 319-50.

Edwards, D. (1995b). Sacks and psychology, Theory and Psychology, 5, 579-596.

Edwards, D. (1997). Discourse and cognition. London and Beverly Hills, CA: Sage.

Edwards, D. (1998). The relevant thing about her: Social identity categories in use. In C. Antaki \& S. Widdicombe (Eds). Identities in talk (pp. 15-33). London: Sage.

Edwards, D., Ashmore, M. \& Potter, J. (1995). Death and furniture: The rhetoric, politics, and theology of bottom line arguments against relativism. History of the Human Sciences, 8, 25-49.

Feyerabend, P. (1975). Against method. London: New Left Books.

Garfinkel, H. (1967). Studies in ethnomethodology. Englewood Cliffs, NJ: Prentice-Hall. 
Garfinkel, H. (2002) Ethnomethodology's program: Working out Durkheim's aphorism. Lanham, MD; Rowman \& Littlefield Publishers.

Hepburn, A. (in press). An introduction to critical social psychology. London; Sage.

Heritage, J.C. \& Greatbatch, D.L. (1991). On the institutional character of institutional talk: The case of news interviews. In D. Boden \& D.H. Zimmerman (Eds.), Talk and social structure: Studies in ethnomethodology and conversation analysis (pp. 93-137). Oxford: Polity.

Heritage, J.C. (1984). A change-of-state token and aspects of its sequential placement. In J.M. Atkinson \& J. Heritage (Eds.), Structures of social action: Studies in conversation analysis (pp. 299-346). Cambridge: Cambridge University Press.

Heritage, J.C. (1997) Conversation analysis and institutional talk: Analysing data. In D. Silverman (Ed.) Qualitative Research: Theory, method and practice (pp. 161-182) London; Sage.

Hutchby, I., \& Wooffitt, R. (1998). Conversation analysis: Principles, practices and applications. Cambridge: Polity.

Lepper, G. (2000). Categories in text and talk. London; Sage.

Lynch, M. (1993). Scientific practice and ordinary action: Ethnomethodology and social studies of science. Cambridge: Cambridge University Press.

Mulkay, M. (1979). Science and the sociology of knowledge. London: Allen \& Unwin.

Phillips, L.J. \& Jorgenson, M.W. (2002). Discourse analysis as theory and method. London; Sage.

Pomerantz, A.M. (1984). Agreeing and disagreeing with assessments: Some features of preferred/dispreferred turn shapes. In J.M. Atkinson \& J. Heritage (Eds.), Structures of social action: Studies in conversation analysis (pp. 57-101). Cambridge: Cambridge University Press. 
Pomerantz, A. (1990/1991) Mental concepts in the analysis of social action, Research on Language and Social Interaction, 24, 299-310.

Potter, J. (1982). Nothing so practical as a good theory: The problematic application of social psychology. In P. Stringer, (Ed.). Confronting social issues: Applications of social psychology (pp. 23-49). London; Academic Press.

Potter, J. (1996) Representing reality: Discourse, rhetoric and social construction. London; Sage.

Potter, J. (2002). Two kinds of natural, Discourse Studies, 4, 539-542.

Potter, J. (2003). Discourse analysis and discursive psychology. In P.M. Camic, J.E. Rhodes and L. Yardley (Eds). Qualitative research in psychology: Expanding perspectives in methodology and design (pp. 73-94). Washington: American Psychological Association.

Potter, J. (in press). Discourse analysis. In M. Hardy \& A. Bryman (Eds) Handbook of Data Analysis. London: Sage.

Potter, J. \& Edwards, D. (2003). Rethinking cognition: On Coulter, discourse and mind, Human Studies, in press.

Potter, J. \& Hepburn, A. (2003). ‘I’m a bit concerned' - Early actions and psychological constructions in a child protection helpline, Research on Language and Social Interaction, in press.

Potter, J. \& Wetherell, M. (1987). Discourse and social psychology: Beyond attitudes and behaviour. London: Sage.

Puchta, C. \& Potter, J. (in press). Focus group interaction: Discourse, moderation and market research. London; Sage.

Roffe, M. (1996). The social organisation of social work. Loughborough University, PhD.

Sacks, H. (1963). Sociological description. Berkeley Journal of Sociology, 8, 1-16. 
Sacks, H. (1992). Lectures on conversation. Vols. I \& II, edited by G. Jefferson. Oxford: Basil Blackwell.

Schegloff, E.A. (1991). Conversation analysis and socially shared cognition. In L. Resnick, J. Levine, S. Teasley (eds.). Perspectives on socially shared cognition (pp. 150-71). Washington, D.C.: American Psychological Association.

Schegloff, E. A. (1999) 'Schegloff's texts’ as ‘Billig's data’: A critical reply, Discourse and Society, 10: 558-572.

Schegloff, E.A. (1997) Whose text? Whose context?, Discourse and Society, 8, 165-187.

Silverman, D. (1997). Discourses of counselling: HIV counselling as social interaction. London; Sage.

Silverman, D. (1998) Harvey Sacks: Social science and conversation analysis. Oxford: Policy Press

Smith, D. (1990). Texts, facts and femininity: Exploring the relations of ruling. London: Routledge.

Te Molder, H. \& Potter, J. (Eds) (in press). Talk and cognition: discourse, mind and social interaction. Cambridge: Cambridge University Press.

ten Have, P. (1998). Doing conversation analysis. London; Sage.

van Dijk, T.A. (1996a) Discourse as structure and process (vol. 1 of Discourse Studies: A multidisciplinary introduction). London; Sage.

van Dijk, T.A. (1996b) Discourse as social interaction (vol. 2 of Discourse Studies: A multidisciplinary introduction). London; Sage.

Wetherell, M. (1998). Positioning and interpretative repertoires: Conversation analysis and post-structuralism in dialogue, Discourse and Society, 9, 387-412. 
Wetherell, M. and Potter, J. (1992) Mapping the language of racism: Discourse and the legitimation of exploitation. Brighton: Harvester/Wheatsheaf, New York: Columbia University Press.

Wetherell, M., Taylor, S. \& Yates, S.J. (Eds)(2001). Discourse theory and practice: A reader. London; Sage.

Widdicombe, S. \& Wooffitt, R. (1995). The language of youth subcultures: Social identity in action. London; Harvester/Wheatsheaf.

Wiggins, S. (2002). Talking with your mouth full: Gustatory mmms and the embodiment of pleasure, Research on Language and Social Interaction, 35, 311-336. 


\section{Box 1 - Discourse Analysis}

What is discourse analysis? The answer to this question gets harder and more complicated every year. Are there 7 different types? Or perhaps two broad orientations? Is discourse treated as a 'thing', as in Continental DA (influenced by Foucault)? In this tradition you might say you have identified two discourses in a set of interviews about some topic. Or is discourse a word that constructs language as active: texts and talk in social practice? Here you are interested in the actions that are done and the practices they contribute to. These two orientations are not always in tension with one another. For example, some discourse analytic work has been interested in how a range of 'resources' get used in discourse practices, where these resources might be words, categories, or broader organizations such as 'interpretative repertoires' (Potter, in press).

Part of the complication has been that different traditions called 'discourse analysis' have emerged in different disciplinary environments. Often these traditions are structured by, and against, the basic issues of the parent discipline - how sentences cohere linguistically into discourse; how social organization is made up; how cognition is respecified in interaction. For a sense of the varied intellectual geography of discourse analysis compare and contrast Phillips \& Jorgenson (2002), van Dijk (1996a,b) and Wetherell et al., (2001). Another complication is that a tradition of specifically 'critical' discourse analysis has emerged mainly in linguistics (see Wodak, this volume); yet in other disciplinary contexts, discourse analysis has often dealt with issues of ideology and asymmetry without the capital C critical preface (see Hepburn, in press, chapter 7).

One of the reasons for writing about discursive psychology instead of discourse analysis is to avoid some of the terminological confusion that makes discourse analysis a highly ambiguous category. 


\section{Box 2 - Interviews and naturalistic data}

Discourse analysis has overwhelmingly been done using interview data, particularly that strand of discourse work that developed within social psychology (Wetherell \& Potter, 1992; Billig, 1992). Without diminishing the importance of this work, there are a number of virtues of working with naturalistic materials:

1) It does not flood the research setting with the researcher's own categories (embedded in questions, probes, stimuli, vignettes and so on);

2) It does not put people in the position of disinterested experts on their own and other's practices, thoughts and so on, encouraging them to provide normatively appropriate descriptions (as many interview and questionnaire studies do);

3) It does not leave the researcher to make a range of more of less problematic inferences from the data collection arena to topic (from interviews about counselling, say, to counselling itself) as the topic itself (counselling, perhaps) is directly studied;

4) It opens up a wide variety of novel issues and concerns that are outwith the prior expectations embodied in questionnaires, experimental formats, interviews questions and so on;

5) It is a rich record of people living their lives, pursuing goals, managing institutional tasks and so on (Potter, 2002). 
Box 3 - Theoretical principles of Discursive Psychology

Discursive psychology can be understood as highlighting three core features of discourse (from Potter, 2003):

1. Action orientation. Discourse is the primary medium of human action and interaction. Actions are not merely free standing, but are typically embedded in broader practices. Some are generic (making invitations); some are specific to settings (air traffic control management of flight crew).

The idea of action orientation discourages the expectation that analysis will discover a one-to-one relation where discrete acts are performed by discrete verbs.

2. Situation. Discourse is situated in three senses. First, it is organized sequentially, such that the primary environment of what is said is what has just come before, and this sets up (although does not determine) what comes next. Second, it may be situated institutionally, such that institutional identities (news interviewee, say) and tasks (managing neutrality in news interviews) may be relevant to (although not determine) what takes place. Third, it can be situated rhetorically, such that descriptions may resist actual or potential attempts to counter them as interested.

3. Construction. Discourse is constructed and constructive. It is constructed in the sense that it is built from various resources (words, of course, but also categories, commonplace ideas, broader explanatory systems). It is constructive in the sense that versions of the world, of events and actions, and of people's phenomenological worlds are built and stabilized in talk in the course of actions. A person may account for their absence at a meeting by constructing a version of the city's traffic problems, or of their own faulty cognitive processing. 


\section{Box 4 - digital records}

The ideal with discourse research has always been to work with the sound and transcript in parallel. There is a wide recognition of the limitations of transcript alone, particularly in capturing subtleties of intonation and inflection. However, working with cassette tape is a pain. If you are comparing two segments of an interview, say, which are 20 minutes apart it can take ages pumping the fast forward and reverse keys to find each of them. Or if you want to consider a set of extracts you might be inserting and ejecting cassettes, rewinding, (inevitably missing the right place and winding forward again) for a considerable part of the research period. The temptation was always to work with the transcript, which has the enormous virtue of being on paper, which is a wonderfully flexible and transportable medium.

Digital sound and video has changed all that. The recording (whether originally recorded in digital or not) can be recorded into PC software. This turns it into a file that can be copied, edited, listened to and so on. If it is saved in MP3 it will also be small, at least compared to the original. Video can be saved as MPEG. Both can be burnt onto CD for easy transport. Extracts can be emailed between researchers. They can be downloaded from web sites in sensible amounts of time, making the provision of recordings alongside paper publications a real possibility. See the journal DA-Online, for example, at www.shu.ac.uk/daol/

We use CoolEdit (from www.syntrillium.com) for most sound recording, manipulation and transcription. This software allows you to step through the recording viewing a physical representation of the sound while hearing. This makes timing pauses and noting overlaps much easier. Segments of interest can be cut and pasted just as with text files. It transforms the practice of transcription and analysis making both much more fluid. Crucially CoolEdit allows the identifying details such as proper names to be disguised (e.g. by reversing or deleting) and speaker's voice quality can be subtly changed to make them unrecognisable while retaining crucial features of vocal delivery. 


\section{Box 5 - Validating analyses}

A range of different validation procedures have been highlighted in discourse analysis and discursive psychology. The following (from Potter, in press b) are most important for the style of discursive psychology discussed here.

1. Participants' orientations. Any turn of talk is oriented to what came before, and sets up an environment for what comes next. At its simplest, when someone provides an acceptance it provides evidence that what came before was an invitation. If an analyst claims that some conversational move is an indirect invitation, say, we would want to see evidence that the recipient is orientating (even indirectly) to its nature as an invitation. Close attention to this turn-by-turn display of understanding provides one important check on analytic interpretations (Heritage, 1997).

2. Deviant cases. Deviant cases play a significant role in the validation of findings. They are often the most analytically and theoretically informative. They can show whether a generalization is robust or breaks down. For example, studies of media interviews show that interviewees rarely treat interviewers as accountable for views expressed in their questions. As Heritage \& Greatbatch (1991) have shown, this is the normal (indeed, normative) pattern. There are occasional deviant cases, where a news interviewer is treated as responsible for some view. However, rather than showing that this pattern is not normative, they show up precisely that it is normative. Cases of departure can lead to considerable interactional trouble, which interferes with the interviewee making their point (Potter, 1996).

3. Coherence. The accumulation of findings from different studies allows new studies to be assessed for their coherence with what comes before. For example, work on the organization of food assessments in mealtime conversations (Wiggins, 2002) builds on, and provides further confirmation of, earlier work on assessments, compliments and news receipts (Heritage, 1984; Pomerantz, 1984). Looked at the other way round, a study which clashed with some of the basic findings in discourse work would be treated with more caution - although if its findings seemed more robust it would be more consequential.

4. Readers' evaluation. One of the most fundamental features of discourse research is that its claims are accountable to the detail of the empirical materials, and that the empirical materials are presented 
in a form that allows readers to make their own checks and judgements. Discourse articles typically present a range of extracts from the transcript alongside the interpretations that have been made of them. This form of validation contrasts with much traditional experimental and content analytic work, where it is rare for anything close to 'raw data' to be included, or for more than one or two illustrative codings to be provided. Sacks' (1992) ideal was to put the reader as far as possible into the same position as the researcher with respect to the materials. Such an ideal is unrealisable, but conversation and discourse analytic work brings it closer than many other analytic approaches. 


\section{Box 6: Discourse Analysis, Ethnomethodology and Conversation Analysis}

Readers familiar with the work of Harvey Sacks will have noted the similarity between some of the materials and concerns in this analysis and Sacks' earliest work on calls to an Emergency Psychiatric Centre (e.g. the first 10 lectures of the Fall 1964 - Spring 1965 series). This raises the interesting and rather complicated question of how discourse analysis differs from, and is related to, ethnomethodology and conversation analysis.

Part of the difficulty in answering this question comes from the spread of different approaches that are called discourse analysis (as noted in Box 1). There is also important variation in the way ethnomethodology is understood - particularly between the 'classic' approach of Garfinkel's Studies in Ethnomethodology and the more recent programme (Garfinkel, 1967, 2002). In addition, there are differences between Sacks' early work on membership categorization, which has had something of a renaissance recently, and the broader conversation analytic tradition that Sacks developed and inspired (see Silverman, 1998). Within this diversity there is considerable convergence amongst some strands of discourse analysis, ethnomethodology and conversation analysis.

To simplify this question, five areas of potential divergence between discourse analysis (at least in the tradition presented here), conversation analysis and ethnomethodology can be highlighted.

1. Construction. Discourse analysis is a constructionist tradition (as we noted in Box 3). However, it differs from other constructionist traditions in social science in its concrete focus on how versions and descriptions are put together to perform actions. The construction and use of descriptions is taken as topic. It is not clear how far this perspective escapes the kinds of critiques of constructionism developed by ethnomethodologists (Button \& Sharrock, 1993 - see commentary in Potter, 1996) and conversation analysts. Ethnomethodologists themselves have a long tradition of studying fact construction (e.g. Smith, 1990), and some of Sacks' earliest work was on description (Sacks, 1963). Much of the disagreement here arises from confusion, or is in emphasis rather than on substantive issues. Hutchby \& Wooffitt's (1998) introduction to conversation analysis has a chapter on fact construction.

2. Cognition. Discourse analysis in this tradition is anti-cognitivist. That is, it rejects the goal of explaining action by reference to underlying cognitive states or entities. Conversation analysts are 
sometimes ambivalent about the status of cognitive entities (Pomerantz, 1990/91; Schegloff, 1991).

Edwards (1995b) has given a reading of Sacks' work that highlights his anti-cognitivism.

Ethnomethodologists have sometimes criticised discourse analytic work for being too cognitivist, although the issue at stake seems to be more that of empirical vs. conceptual analysis (see Potter \& Edwards, 2003). Overall, there are a range of interesting and productive disagreements that are still being worked through by interaction researchers (see papers in te Molder \& Potter, in press).

3. Interviews. Much of the earlier work in discourse analysis was done using interviews. Indeed, two of the most influential studies (Billig, 1992 and Wetherell \& Potter, 1992) used interviews to generate most of their data. Conversation analysts and ethnomethodologists have largely rejected interviews as a research tool (although they have been treated as a topic of study). This difference is less pronounced now as discourse researchers have started to accept some of the implications of the critique of interviews (e.g. in Widdicombe \& Wooffitt, 1995), and there is an increasing focus on naturalistic materials (as seen in the current chapter).

4. Resources. Discourse analysis has had a focus on the resources drawn on in practices as well as the practices themselves. This is seen particularly in early work that studied 'interpretative repertoires' (Potter \& Wetherell, 1987). One of the issues at stake is how far such resources can be studied independently of the practices they are a part of. There is no easy resolution of this. A similar tension is apparent in the early Sacks' interest in membership categorization analysis and the later emphasis on sequential analysis. In his introduction to the lectures Schegloff suggests that the later Sacks is a more coherent and is less open to a promiscuous proliferation of interpretations. Nevertheless, the membership categorization tradition continues to be influential (Lepper, 2000). 5. Epistemology. Discourse analysis has been strongly influenced by work in the sociology of scientific knowledge, and has often adopted a methodologically relativist position. Indeed, discourse analysts have provided some of the most explicit defences of relativism in recent social science (Edwards, et al., 1995). Conversation analysts in particular have tended to take a more robust view of science and knowledge. Ethnomethodological researchers have a position of considerable complexity which is different form CA in some respects, but not one that chimes with the relativist thinking from discourse analysis (Lynch, 1993). There are certainly differences here, although they are mainly at the level of meta-theory. They are unlikely to make a major difference to research 
practice. Whether a relativist or not, there is still the issue of how to make a coherent choice between different analytic claims, say. 
Figure 2 - general permissions letter

Dear [Name]

I am writing to ask if you will help me with my research. I am a lecturer in Psychology at Loughborough University. I am studying the process of counselling on telephone help lines, using the recently developed approaches of discourse and conversation analysis.

My aim is to highlight the rich and complex set of discursive and conversational practices that are used by both counsellors and young people. This kind of study has been especially useful in family therapy, social work and relationship counselling, and I have good links with some of the key analysts in this field.

The research will not involve extra work for you or your team in the form of questionnaires or interviews. What would be involved would be some counsellors making records of a small number of sessions using a standard tape recorder. The research will be conducted fully within BPS ethical guidelines - all people involved would need to give their informed consent, and I will ensure unqualified anonymity at all stages of the research. No participants will be identified by name, and all tapes will be transcribed and listened to only by myself and a limited number of research colleagues. For any published output identifying details will be comprehensively anonymized. I have consulted carefully with other researchers who have dealt with 
sensitive topics of this kind such as relationship counselling talk and social workers' assessments of sexually abusing parents. I have also published a number of articles exploring the issue of school bullying, employing these types of qualitative methods on interview data with teachers and pupils.

I realise that although most people like to help researchers in principle, in practice this involves some extra work in what is already a delicate and demanding job where trust and confidentiality are a premium. What I can offer to counsellors and staff members in return is to share my results with you in the form of a feedback report and workshop. Practitioners in other fields have found the detailed transcriptions of sessions particularly illuminating as they provide an unusually rich record of their interactions, highlighting often unnoticed features. I believe that the detailed analytical points will allow deeper insights into the processes of counselling and other issues of concern to participants. I expect that the research project overall would lead to recommendations for counselling training and strategies, for enhancing existing literature available to counsellors, parents and children, and for informing policy intervention strategies.

Thank you for your time, and I look forward to hearing from you in due course.

Yours sincerely, 
Figure $2-$ abstract of concerns paper

\title{
'I'M A BIT CONCERNED' - EARLY ACTIONS AND PSYCHOLOGICAL CONSTRUCTIONS IN A CHILD PROTECTION HELPLINE
}

\begin{abstract}
This paper analyses early actions in 50 calls reporting cases of abuse to a national child protection helpline in the UK (the National Society for the Prevention of Cruelty to Children helpline). It focuses in particular on the early turns in the caller's 'reason for call', and in particular a class of constructions in which the caller describes him or herself as being 'concerned about x' (or similar). Analysis of the corpus of calls suggests concern constructions are canonical early elements of the reason-for-call sequence. Concern constructions (a) are oriented to as a pre-move in the caller's reason for call; (b) project the unpacking of concerns in a way oriented to the NSPCC's institutional role; (c) attend to epistemological asymmetries between caller and call taker and remove the requirement for disaffiliative next actions such as asking for the basis of claims; (d) provide a way for the Child Protection Officer to take abuse claims seriously while not presupposing their truth; (e) display an appropriate caller stance. These observations are supported by an analysis of deviant cases. The broader implications of this study for the relation between psychology, interaction and institutions are discussed.
\end{abstract}


